\title{
ANALISIS FAKTOR-FAKTOR YANG MEMPENGARUHI KEINGINAN MASYARAKAT UNTUK MENERIMA PERBANKAN SYARIAH
}

\author{
Oleh: \\ Reni Yendrawati \\ Achmad Tirto Sudiro
}

\section{ABSTRACT}

This research titled "Analyzes the Factors that have an Effect Towards Society Intention to Accept on Islamic" which is purposed to test the factors that influent the Intention to accept of society into Islamic Banking as an alternative of financial. This research use source not only from Indonesian research and literature but also from foreign research and literature which is focus om internal variable, economic factors and religious factors also external variable that is quality of service, geographic acces and brand then test the influence of each its variable into the dependent variable which is intention to accept. Test on ths research use doubled regression formula.

This research takes sample society on Daerah Istimewa Yogyakarta. Sampling based on society jobs which classified into four class that are Mahasiswa, Pegawai Negeri Sipil, Pegawai Swasta and UKM (Usaha Kecil dan Menengah). It's use accidental sampling technic, that spread 200 of quesiner but only 134 that can be process. Data were analyzed using statistical software SPSS version 16.0 and AMOS version 16.0.

From five hypothesis only one that prove influencing the intention to accept on Islamic Banking. It's show that Daerah Istimewa Yogyakarta society intention to accept on Islamic Banking as an alternatve of financial institutions only influenced by religious factors not economic factors, quality of service, geographic acces or brand

Key Words: Economic factors, Religious factors, Quality of Service, Geographic acces, Brand, Intention to Accept, Islamic Banking. 
Salah satu konsep yang sering dibicarakan oleh pära èkonom baik di dunia maupun di Indonesia saat ini adalah Perbankan Syariah. Konsep tentang perbankan syariah menerapkan ajaran Islam dalam sistem perbankan yang memiliki hubungan terhadap transaksi yang bebas dari bunga (Caragata, 2000).

Perbedaan konsep antara perbankan syariah dan perbankan konvensional dapat mempengaruhi penilaian nasabah dalam menetukan pilihannya. Oleh karena itu, perbankan syariah harus menawarkan kualitas spesial agar mampu bersaing dengan perbankan konvensional.

Metawa dan Almosawwi (1998) menemukan bukti bahwa pilihan nasabah dalam memilih bank syariah dipengaruhi oleh faktor agama, dimana nasabah memiliki pegangan kuat akan ajaran Islam.Erol dan El-Bdour (1989) menemukan bahwa motif memilih bank syariah sebagai tempat menabung bukanlah agama, melainkan keuntungan (profit).Lebih lanjut penelitian Erol et al.(1990, dalam penelitian Bank Indonesia tahun 2000) menunjukkan bahwa nasabah memilih bank syariah dikarenakan servis yang cepat dan efisien dan reputasi bank syariah. Penelitian yang dilakukan oleh Naser, Jamal dan Al-Khatib (1999, terdapat dalam penelitian Khoiruddin (2001) menunjukkan bahwa nasabah memilih bank syariah disebabkan baik oleh faktor ekonomi (profit) maupun faktor agama, dimana faktor yang memotivasi nasabah untuk memilih bank syariah adalah reputasi bank, alasan agama, persepsi bank syariah mengaplikasikan ajaran Islam serta keuntungan yang akan didapat nantinya lebih besar dibanding bank konvensional. Sedangkan menurut Amali Rivai (2002), Perbankan syariah sudah tidak saatnya lagi mengandalkan "spiritual markef" yang hanya diisi oleh segmen syariah loyalist, yaitu mereka yang memilih bank semata-mata hanya karena alasan agama.

Kecenderungan dimasa yang akan datang diperkirakan bahwa segmen yang digarap oleh bank syariah mulai bergeser dari syariah loyalist ke floating market. Hal ini disebabkan karena konsumen semakin rasional, dengan tetap mengutamakan kualitas pelayanan serta benefit lainnya yang ditawarkan daripada hanya dengan melakukan pendekatan emosional. Untuk mengantisipasi kecenderungan tersebut pertu adanya kesiapan infrastruktur dan sumberdaya yang dimiliki oleh bank syariah saat ini agar mampu berkembang seperti layaknya bank konvensional. Dalam penelitiannya Khoirunissa (2003) menemukan adanya hubungan antara faktor ekonomi dan faktor agama terhadap preferensi masyarakat untuk menggunakan jasa perbankan syariah.

Banyak tantangan dan permasalahan yang dihadapi dalam pengembangan perbankan syariah terutama di Indonesia. Permasalahan yang muncul antara lain adalah rendahnya pengetahuan masyarakat terhadap perbankan syariah terutama yang disebabkan dominasi perbiankan konvensional. Berikut ini dikemukakan beberapa kendala yang muncul sehubungan dengan pengembangan perbankan syariah (Subardjo dalam Antonio,1999 yang terdapat pada penelitian Bank Indonesia): 
1) Pemahaman masyarakat yang belum tepat terhadap kegiatan operasional bank syariah.

2) Peraturan perbankan yang berlaku belum sepenuhnya mengakomodasi operasional bank syariah.

3) Jaringan kantor bank syariah yang belum luas.

4) Sumber daya manusia yang memiliki keahlian dalam bank syariah masih sedikit.

Penelitian ini bertujuan untuk mengungkap faktor-faktor apa saja yang mempengaruhi masyarakat di D.I.Yogyakarta untuk menerima (Intention to accept / Acceptability) keberadaan perbankan syariah.

\section{B. TELAAH TEORI}

\section{Perilaku Konsumen Islam}

Teori perilaku konsumen adalah salah satu faktor utama dibidang ekonomi. Dalam teori perilaku konsumen, keinginan konsumen untuk mendapatkan sejumlah barang maupun jasa dapat dijelaskan. Konsumen akan membeli lebih ketika harga rendah dan akan mengurangi pembelian ketika harga barang atau jasa tersebut tinggi.

Perilaku konsumen Islam merujuk pada kepatuhan terhadap hukum Islam, yaitu apa yang diperbolehkan dan apa yang tidak diperbolehkan. Umat Islam diperbolehkan memenuhi kebutuhan hidupnya dengan mempergunakan seluruh sumber daya yang berada di Bumi namun tidak diikuti dengan sikap yang berlebihan atau mewah karena Islam tidak mengajarkan untuk hidup secara mewah atau berlebihan.

Analisis terhadap sikap atau perilaku konsumen dapat menghasilkan manfaat diagnostik maupun prediktif. Mengidentifikasi pangsa pasar yang reseptif, mengevaluasi kegiatan pemasaran yang sekarang dan yang potensial, dan meramalkan perilaku masa datang adalah sebagian dari cara-cara utama di mana sikap dapat membantu pengambilan keputusan pemasaran. Sikap didefinisikan sebagai evaluasi menyeluruh. Intensitas, dukungan, dan kepercayaan adalah sifat penting dari sikap. Masing-masing sikap ini akan bergantung pada kualitas pengalaman konsumen sebelumnya dengan obyek sikap. Ketika konsumen mengakumulasi pengalaman baru, sikap dapat berubah.

\section{Akseptabilitas}

Akseptabilitas menurut Kamus Besar Bahasa Indonesia adalah kata serapan yaing berasal dari bahasa Inggris acceptability. Dalam Kamus Bèsar Bahasa Indonesia akseptabilitas memiliki arti keberterimaan, kemampuan dan keinginan untuk menerima (sesuatu) dan perilaku untuk menerima. 


\section{Kuialitas Layanan (Jasa)}

Kualitas adalah keseluruhan ciri-ciri dan karakteristik dari suatu produk atau layanan menyangkut kemampuan untuk memenuhi kebutuhan-kebutuhan yang telah ditentukan atau yang bersifat laten (evans dan Dean, 2003). Sedangkan menurut filsafat Jepang kualitas adalah "zero defect" mengerjakan pertama kali dengan benar.

Menurut Wyckof dalam Lovelock (1988) pengertian kualitas layanan adalah tingkat kesempurnaan yang diharapkan dan pengendalian atas kesempurnaan tersebut untuk memenuhi keinginan konsumen.

\section{Perbankan Syariah dan Pemberdayaan Umat}

Menurut UU No. 10 tahun 1998 tentang Perubahan UU No. 7 tahun 1992 tentang Perbankan, disebutkan bahwa Bank Syariah adalah Bank Umum yang melaksanakan kegiatan usaha berdasarkan prinsip syariah yang dalam kegiatannya memberikan jasa dalam lalu lintas pembayaran. Dalam menjalankan aktivitasnya, Bank Syariah menganut prinsip-prinsip sebagai berikut:

\section{a. Prinsip Keadilan}

Prinsip ini tercermin dari penerapan imbalan atas dasar bagi hasil dan pengambilan margin keuntungan yang disepakati bersama antara Bank dengan Nasabah.

\section{b. Prinsip Kesederajatan}

Bank Syariah menempatkan nasabah penyimpan dana, nasabah pengguna dana, maupun Bank pada kedudukan yang sama dan sederajat. Hal ini tercermin dalam hak, kewajiban, risiko, dan keuntungan yang berimbang antara nasabah penyimpan dana, nasabah pengguna dana, maupun Bank.

\section{c. Prinsip Ketentraman}

Produk-produk Bank Syariah telah sesuai dengan prinsip dan kaidah Muamalah Islam, antara lain tidak adanya unsur riba serta penerapan zakat harta. Dengan demikian, nasabah akan merasakan ketentraman lahir maupun batin.

Pengertian prinsip syariah menurut UU No.10/1998 adalah aturan perjanjian berdasarkan hukum Islam antara bank dan pihak lain untuk penyimpanan dana dan atau pembiayaan kegiatan usaha, atau kegiatan lainnya yang dinyatakan sesuai dengan syariah.

\section{Tujuan Bank Syariah}

Beberapa tujuan bank syariah diantaranya adalah sebagai berikut :

a. Menciptakan suatu keadilan dibidang ekonomi dengan meratakan pendapatan melalui kegiatan investasi agar tidak terjaci kesenjangan yang besar antara pemilik modal dengan pihak yang nembutuhkan modal. 
b. Meningkatkan kualitas hidup umat dengan membuka peluang berusaha lebih besar terutama kelompok miskin, yang diarahkan kepada kegiatan usaha yang produktif menuju terciptanya kemandirian usaha.

c. Menanggulangi masalah kemiskinan, berupa pembinaan nasabah yang lebih menonjol sifat kebersamaan dari siklus usaha yang lengkap, seperti program pembinaan pengusaha produsen, pembinaan konsumen, pengembangan modal kerja dan pengembangan usaha bersama.

d. Menyelamatkan ketergantungan umat islam terhadap perbankan nonsyariah (konvensional).

\section{PENELITIAN TERDAHULU DAN PENGEMBANGAN HIPOTESIS}

\section{Faktor Ekonomi}

Metawa dan Almosawwi dalam penelitian Khoiruddin (2001) menemukan bukti bahwa pilihan nasabah dalam memilih bank syariah dipengaruhi oleh faktor agama, dimana nasabah memiliki pegangan kuat akan ajaran Islam. Selain itu, pilihan nasabah juga dipengaruhi oleh faktor keuntungan (profit), keluarga dan teman serta lokasi dari bank itu sendiri. Faktor-faktor tersebut menjadi karakteristik responden, seperti umur, pendapatan dan tingkat pendidikan. Menurut Ratnawati et al. (2001) hasil analisis model logit menunjukan bahwa bank syariah ternyata lebih diminati kalangan berpenghasilan menengah ke bawah yang dipengaruhi oleh faktor ekonomi. Berdasarkan beberapa penelitian diatas maka hipotesis dirumuskan sebagai berikut:

H1 : Faktor ekonomi berpengaruh positif terhadap keinginan masyarakat untuk menerima perbankan syariah

\section{Faktor Agama}

Menurut Kotler (1994), perilaku konsumen dipengaruhi oleh, faktor sosial budaya serta personalitas dan keyakinan (agama) seperti halnya faktor psikologi.

Motivasi seseorang dalam beraktivitas sangat erat kaitannya dengan kondisi psikologi (kejiwaannya). Jika seseorang melakukan kegiatan ekonomi seperti menabung di bank syariah yang didorong oleh faktor agama maupun ekonomi akan sangat sesuai dengan apa yang dipaparkan dalam ajaran Islam.

Menurut Amani Rivai et al. (2002) perbankản syariah sudah tidak saatnya lagi mengandalkan "spiritual markef" yang hanya diisi oleh segmen syariah loyalist, yaitu mereka yang memilih bank semata-mata hanya karena alasan agama. Kecenderungan dimasa yang akan datang diperkirakan bahwa segmen yang digarap oleh bank syariah mulai bergeser dari syariah loyalist ke floating market. Hal ini disebabkan karena konsumen semakin rasional, dengan tetap mengutamakan kualitas pelayanan serta benefit lainnya yang ditawarkan daripada hanya dengan melakukan pendekatan emosional. Untuk mengantisipasi kecenderungan tersebut perlu adanya kesiapan infrastruktur dan sumberdaya yang dimiliki oleh bank syariah saat ini agar mampu berkembang seperti layaknya bank konvensional. 
Reni Yendrawati dan Achmad Tirto Sudiro: Analisis Faktor-faktor ...

Penelitian yang dilakukan Erol dan El-Bdour (1989) seperti yang dikutip pada penelitian Delta Khoirunissa menemukan bukti bahwa faktor agama tidak berpengaruh terhadap keinginan masyarakat untuk menggunakan jasa perbankan syariah.: Berdasarkan hasil penelitian diatas maka dirumuskan hipotesis sebagai berikut:

H2: Faktor agama berpengaruh positif terhadap keinginan masyarakat untuk menerima perbankan syariah.

\section{Faktor Kualitas Pelayanan}

Apabila perbankan syariah bisa memberikan pelayanan yang prima dan profesional serta memiliki kinerja yang exellence, maka dapat dipastikan umat Islam akan lebih percaya terhadap perbankan syariah. Para praktisi bank syariah harus dapat meyakinkan ummat Islam bahwa bank syari'ah itu lebih baik.

Pada sebuah studi tentang sikap konsumen Amerika terhadap bank komersial, Kaynak (2004) menemukan tiga atribut penting yang menjadi pertimbangan konsumen dalam memilih bank; ketersediaan ATM, pelayanan yang cepat dan efisien, serta respon petugas yang cepat. Selain itu, penelitian tentang persepsi konsumen di Malaysia menemukan bahwa persepsi konsumen terhadap bank syariah terdiri terdiri dari beberapa dimensi; pemanfaatan fasilitas perbankan, pengetahuan terhadap perbankan Islam, peranan konsumen dalam memilih produk perbankan telah dilakukan (Nurafifah dan Haron 2001).

Penelitian yang dilakukan Gerrard dan Cunningham (1997) menemukan bukti bahwa baik itu kaum muslim maupun non-muslim tidak memiliki perbedaan sikap dalam memilih bank syariah, dimana mereka memilih bank syariah disebabkan oleh kualitas pelayanan yang baik dan memadai. Berdasarkan hasil penelitian diatas maka dirumuskan hipotesis sebagai berikut:

H3 : Faktor kualitas pelayanan berpengaruh positif terhadap keinginan masyarakat untuk menerima perbankan syariah.

\section{Faktor Letak Geografis}

Pembukaan kantor-kantor cabang baru harus menempati lokasi yang strategis agar memudahkan nasabah untuk mempergunakan jasa perbankan syariah. Menurut Nasrudin et al (2000) belum diketemukan pola khusus geografis yang menjelaskan pengaruh letak geografis terhadap perkembangan bank syariah. Selanjutnya, penelitian Almossawi (1991; seperti dikutip dari Amali Rivai et al.) di Bahrain mengidentifikasi lima atribut penting yang dipertimbangkan konsurien dalam memilih bank, dimana 2 diantaranya adalah ketersediaan ATM dibeberapa lokasi dan kantor cabang dilokasi strategis atau dengan kata lain letak geografis akan mempengaruhi / rerkembangan bank syariah. Berdasarkan penelitian tersebut maka hipotesis dirumuskan sebagai berikut:

H4: Faktor letak geografis berpengaruh positif terhadap keinginan masyarakat untuk menerima perbankan syariah. 


\section{Faktor Merk (branded)}

Menurut Hapsari (2002) dari sekian banyak produk atau jasa yang ditawarkan oleh perusahaan, maka ada beberapa merek yang dikenal dan yang tidak dikenal. Langkah pertama dalam mendapatkan informasi internal adalah memisahkan antara merek yang dikenal dan diingat oleh konsumen dan yang tidak dikenal atau diingat oleh konsumen. Dari produk yang dikenal tersebut dipisahkan lagi menjadi produk yang menjadi pilihan konsumen atau diterima konsumen (consideration set levoked set), produk yang bersifat indiferen (inert set), produk yang tidak dapat diterima oleh konsumen (inept set), dan produk yang terabaikan (overlooked brands).

Almosawwi (1991; seperti dikutip dari Amali Rivai et al.) menemukan bahwa reputasi merupakan salah satu faktor penting bagi konsumen untuk menggunakan jasa perbankan. Berdasarkan dua penelitian diatas maka hipotesis dirumuskan sebagai berikut:

H5 : Faktor Branded /Merk berpengaruh positif terhadap keinginan masyarakat untuk menerima perbankan syariah.

\section{METODE PENELITIAN}

Data yang digunakan dalam penelitian ini adalah data primer, yaitu data yang langsung diperoleh dari sumber data pertama di lokasi penelitian atau objek penelitian. Data diambil dengan menyebarkan kuesioner kepada orang yang memenuhi kriteria yang ditetapkan. Kriteria yang ditetapkan tersebut adalah masyarakat D.I.Yogyakarta yang belum menggunakan produk perbankan syariah.

\section{Populasi dan Sampel}

- Populasi

Populasi dalam penelitian ini adalah seluruh elemen masyarakat D.I.Yogyakarta yang belum menggunakan produk perbankan syariah.

\section{- Sampel}

Pengambilan sampel dilakukan dengan accidental sampling, yaitu metode pengambilan sampel yang didasarkan pada kemudahan (convenience) dimana sampel dapat terpilih karena berada pada waktu, situasi dan tempat yang tepat (Prasetyo \& Lina, 2005).Sampel dibatasi pada elemen pekerjaan masyarakat tertentu yaitu, wiraswasta (UKM), pegawai swasta, pegawai negeri dan mahasiswa. Elemen pekerjaan wirașasta (UKM); pegawai negeri dan swasta dipilih dalam penelitian ini adalah karena perbankan syariah tidak hanya menyentuh sektor moneter namun juga sektor riil. Selain itu UKM juga merupakan target pasar terbesar dari perbankan syariah. Mahasiswa dipilih dalam penelitian ini adalah karena mereka memiliki pengetahuan yang baik akan lembaga keuangan pada umumnya dan perbankan syariah pada khususnya. 
Reni Yendrawati dan Achmad Tirto Sudiro: Analisis Faktor-faktor ...

\section{Variabel Variabel Penelitian}

\section{a. Kualitas Pelayanan}

Kualitas layanan merupakan perbandingan antara layanan yang dirasakän (persepsi) konsumen dengan kualitas layanan yang diharapkan konsumen. Jika kualitas layanan yang dirasakn sama atau melebihi kualitas layanan yang diharapkan, maka layanan diktakan berkualitas dan memuaskan . (Parasuman, et al. 1988).

\section{b. Ekonomi}

Ekonomi adalah besarnya tingkat return yang diberikan oleh bank dan jumlah pendapatan (Khoiruddin, 2003).

\section{c. Agama}

Agama adalah keinginan untuk memenuhi tuntunan ajaran agama Islam terutama mengenai prinsip riba (Khoiruddin, 2003).

\section{d. Letak Geografis}

Letak Geografis adalah banyaknya jumlah bank syariah yang tersebar di dalam suatu wilayah serta jarak lokasi bank dengan pusat kegiatan masyarakat (Amali Rivai, 2006).

\section{e. Branded (Merk)}

Number of brands purchase (jumlah merek yang dibeli), yaitu tingkat . persentase pelanggan dari suatu produk untuk hanya membeli satu merk, dua merek, tiga merk, dan seterusnya. Pelanggan yang loyal umumnya akan melanjutkan pembelian merek tersebut walaupun dihadapkan pada banyak alternatif merk produk pesaing yang menawarkan karakteristik jasa yang lebih unggul dipandang dari berbagai sudut atributnya. Bila banyak pelanggan dari suatu merek masuk dalam kategori ini berarti merek tersebut memiliki brand equity yang kuat (Alida Palilati,2007).

\section{Uji Validitas dan Reliabilitas}

Uji validitas dalam penelitian ini menggunakan software Amos versi 16.0 . Uji validitas digunakan untuk mengetahui bahwa unobserved variable dapat diukur dengan menggunakan masing-masing kontruk observed variable, dengan menggunakan Confimatory Factor Analysis.(CFA) atau biasa disebut dengan analisis faktor. Apabila nilai factor loading dari tiap-tiap konstruk lebih dari $0,5(\lambda>0,5)$ dengan tingkat signifikansi kurang dari $5 \%(P<0,05)$, maka dapat dinyatakan valid, atau dengan kata lain bahwa unobserved variable dapat diukur dengan menggunakan masing-masing konstruk observed variable.

Pengujian reliabilitas setiap variabel dilakukan dengan Cronbach Alpha Coeficient. Data yang diperoleh akan dapat dikatakan reliab'e apabila nilai Cronbach Alpha. lebih besar atau sama dengan 0,6 (Nunnal./, 1967 dalam Ghozali, 2005). Dalam penelitian ini Uji reliabilitas mengguanakan bantuan software SPSS ver. 16.0 


\section{Deskripsi Responsden}

Analisis ini diperlukan untuk menguraikan data-data yang diperoleh dari responden atas penyebaran kuesioner. Dalam analisis ini dilakukan pengamatan terhadap konsumen maupun calon konsumen (masyarakat yang belum menggunakan produk perbankan syariah) dan tanggapan mereka terhadap faktor menerima perbankan syariah di Daerah Istimewa Yogyakarta sehingga mempengaruhi keinginan mereka untuk menerima perbankan syariah.

\section{Pengujian Hipotesis}

Pengujian hipotesis penelitian ini menggunakan model pengujian regresi berganda dengan bantuan amos versi 16.0. Analisis regresi pada dasamya adalah studi mengenai ketergantungan variabel dependen (terikat) dengan satu atau lebih variabel independen (bebas) dengan tujuan mengestimasi dan/atau memprediksi rata-rata populasi atau nilai rata-rata variabel dependen berdasarkan nilai variabel independen yang diketahui (Gujarati, 2003 dalam Ghozali 2005).

Berdasar hipotesis dalam penelitian ini (seperti pada gambar model penelitian) maka ditransformasikan ke dalam persamaan regresi berikut:

\section{ItA $=\alpha+\beta 1 . E C O+\beta 2 . R E L I G+\beta 3 . Q 0 S+\beta 4 . G E O+\beta 5 . B R A N D+\varepsilon$}

Keterangan :

\begin{tabular}{|c|c|c|c|}
\hline ItA & $=$ Intention to Accept & GEO & $=$ Letak Geografi \\
\hline $\boldsymbol{\alpha}$ & $=$ Konstanta & BRAN & $\mathrm{D}=$ Branded (merk/reputasi) \\
\hline$\beta$ & $=$ Koefisien Regresi & $\varepsilon$ & $=$ Error \\
\hline $\mathrm{CO}$ & $=$ Ekonomi & QoS & $=$ Kualitas Pelayanan \\
\hline
\end{tabular}

RELIG = Agama

dari rumus tersebut akan diestimasi masing-masing pengaruh dari 5 variabel bebas yang ada, yaitu ekonomi, agama, kualitas pelayanan, letak geografi serta brand (merk/reputasi). Ke 5 variabel yang ada diestimasi akan memberi pengaruh positif terhadap keinginan untuk menerima (Intention to Accept) perbankan syariah. Dengan menggunakan software Amos ver. 16.0 masing-masing variabel independent akan dilihat pengaruhnya terhadap variabel dependent melalui nilai probabilitas pada $t$ hitung. Bila probabilitas $\mathrm{t}$ hitung lebih kecil dari pada $\alpha$, maka hipotesa tersebut gagal ditolak (Ho ditolak). 


\section{Deskripsi Responden}

Diskripsi responden berdasar jenis kelamin, terdapat pada tanbel 2,berdasar wilayah tempat tinggalmterdapat pada tabel 3 , berdasar jenis pekerjaan terdapat pada tabel 4 dan berdasar tingkat pendidikan terakhir terdapat pada tabel 5.

\section{Uji Validitas}

- Berdasarkan TABEL 6 dapat diketahui bahwa eco1, eco2, eco3, eco4, eco5 dan eco6 yang merupakan indikator pada variabel Ekonomi dinyatakan valid, karena memiliki nilai factor loading (Estimate) di atas 0,5 $(\lambda=0,5)$ dengan tingkat signifikansi di bawah $5 \%(P<0,05)$.

- Berdasarkan TABEL.7 dapat diketahui bahwa relig1, relig2, relig3, relig4, relig5 dan relig6 yang merupakan indikator pada variabel agama dinyatakan valid, karena memiliki nilai factor loading (Estimate) di atas $0,5(\lambda=0,5)$ dengan tingkat signifikansi di bawah $5 \%(P<0,05)$.

- Berdasarkan TABEL 8 dapat diketahui bahwa qof1, qof2, qof3, qof4, qof5, qof6, qof7, qof8, qof9, qof10 dan qof11 yang merupakan indikator pada variabel kualitas pelayanan dinyatakan valid, karena memiliki nilai factor loading (Estimate) di atas $0,5(\lambda=0,5)$ dengan tingkat signifikansi di bawah $5 \%(P<0,05)$.

- Berdasarkan TABEL 9 dapat diketahui bahwa geo1, geo2, geo3 dan geo4 yang merupakan indikator pada variabel letak geografis dinyatakan valid, karena memiliki nilai factor loading (Estimate) di atas $0,5(\lambda=0,5)$ dengan tingkat signifikansi di bawah $5 \%(P<0,05)$.

- Berdasarkan TABEL 10 dapat diketahui bahwa bra1, bra2, bra3 dan bra4 yang merupakan indikator pada variabel brand/merkdinyatakan valid, karena memiliki nilai factor loading (Estimate) di atas $0,5(\lambda=0,5)$ dengan tingkat signifikansi dibawah $5 \%(P<0,05)$.

- Berdasarkan TABEL 11 dapat diketahui bahwa aksep1, aksep2, aksep3, aksep4 dan aksep5 yang merupakan indikator pada variabel keinginan untuk menerima dinyatakan valid, karena memiliki nilai factor loading (Estimate) di atas $0,5(\lambda=0,5)$ dengan tingkat signifikansi di bawah $5 \%$ $(\mathrm{P}<0,05)$.

\section{Uji Reliabilitas}

Berdasarkan pada Tabel.12 dapat disimpulkan bahwa semua pernyataan yang digunakan untuk mengukur masing-masing. variabel penelitian dapat diandalkan atau reliable, karena memiliki nilai Cronbach's Alpha di atas nilai kritis $\cdot(>0,60)$. 


\section{Uji Hipotesis}

Data Uji Hipotewsis mwenunjukkan yang ada pada TABEL 4.13 dan.

TABEL 14 mewnunjukkan bahwa:

- Uji siginifikansi terhadap hipotesis 1 tidak terbukti secara signifikan; karena diperöleh nilai pröbabilitas 0,582 atau lebih besar dari 0,05 yang berarti tidak signifikan pada taraf signifikansi $5 \%$ (Ho gagal ditolak). Hasil. estimasi pengaruh faktor ekonomi terhadap keinginan masyarakat untuk menerima perbankan syariah diperoleh koefisien jalur (standardized regression weight estimate) $=0,089$. Artinya pengaruh antara variabel ekonomi terhadap keinginan masyarakat untuk menerima perbankan syariah adalah positif.

- Uji signifikansi terhadap hipotesis 2 terbukti secara signifikan, karenas diperolè nilai probabilitas 0,011 atau lebih kecil dari 0,05 yang berarti signifikan pada taraf signifikansi 5\% (Ho ditolak). Hasil estimasi pengaruh faktor agama terhadap keinginan masyarakat untuk menerima. perbankan syariah diperoleh koefisien jalur (standardized regression weight estimate) $=0,583$. Artinya pengaruh antara variabel agama - terhadap keinginan masyarakat untuk menerima perbankan syariah. adalah positif.

- Uji signifikansi temadap hipotesis 3 tidak terbukti secara signifikan, karena diperoleh nilai probabilitas 0,094 atau lebih besar dari 0,05 yang - berarti tidak signifikan pada taraf signifikansi 5\% (Ho gagal ditolak). Hasil estimasi pengaruh kualitas pelayanan terhadap keinginan masyarakat untuk menerima perbankan syariah diperoleh koefisien jalur (standardized regression weight estimate) $=0,269$. Artinya pengaruh antara variabel kualitas pelayanan terhadap keinginan masyarakat untuk menerima perbankan syariah adalah positif.

- - Uji signifikansi terhadap hipotesis 4 tidak terbukti secara signifikan, - karena diperoleh nilai probabilitas 0,057 atau lebih besar dari 0,05 yang berarti tidak signifikan pada taraf signifikansi $5 \%$ (Ho gagal ditolak). Hasil estimasi pengaruh faktor letak geografis terhadap keinginan masyarakat úntuk menerima perbankan syariah diperoleh koefisien jalur (standardized regression weight estimate) $=0 ; 304$. Artinya pengaruh antara variabelletak geografis terhadap keinginan masyarakat untuk menerima perbankan syariah adalah. positif.

- Uji signifikansi terhadap hipotesis: 5 tidak terbukti secara signifikan, ' karena diperoleh nilai probabilitas 0,697 atau lebih besar dari 0,05.yang berarti tidak signifikan pada taraf signifikansi $5 \%$ (Ho gagal ditolak). Hasil' estimasi pengaruh fáktor branded/merk terhadap keinginan masyarakat uñtuk menerima perbankan syariah diperoleh koefisien jalur (standardized regression weight estimate) $=0,057$. Artinya pengaruh antara variabelbrand/merk terhadap keinginan masyarakat untuk menerima perbankan syariah adalah positif. 
Reni Yendrawati dan Achmad Tirto Sudiro: Analisis Faktor-faktor ...

\begin{tabular}{c|c|c|}
\hline F. PENUTUP . . &. \\
\hline
\end{tabular}

Penelitian ini bertujuan untuk menguji faktor-faktor yang dapat mempengaruhi keinginan masyarakat untuk menerima perbankan syariah. Penelitian ini dianalisa dengan Regresi berganda. Dari hasil analisis yang telah dilakukan atas dasar hasil pengolahan data penelitian, dapat ditarik kesimpulan sebagai berikut:

1. Faktor ekonomi, faktor kualitas pelayanan, faktor letak geografis serta faktor brand/merk tidak terbukti dapat mempengaruhi keinginan masyarakat untuk menerima perbankan syariah.

2. Faktor agama terbukti dapat mempengaruhi mempengaruhi keinginan masyarakat untuk menerima perbankan syariah.

\section{Keterbatasan dan Saran Penelitian Selanjutnya}

Penelitian ini memiliki sejumlah keterbatasan yang mungkin mempengaruhi hasil penelitian yang ingin dicapai, antara lain:

1) Data yang dikumpulkan dalam penelitian ini hanya mencakup 1 wilayah penelitian, yaitu hanya di Daerah Istimewa Yogyakarta. Penelitian yang akan datang sebaiknya juga mengumpulkan data dari daerah lain yang memiliki karakteristik masyarakat seperti Daerah Istimewa Yogyakarta.

2) Data yang dikumpulkan sebagian besar dari masyarakat yang belum maupun telah menggunakan jasa perbankan syariah sehingga menyebabkan jumlah sampel yang mungkin tidak mewakili populasi yang ada. Penelitian yang akan datang sebaiknya memisahkan sampel antara masyarakat yang telah menggunakan dengan yang belum menggunakan perbankan syariah.

3) Penelitian ini menggunakan data primer, sehingga olahan dan analisis data berdasarkan pada kuesioner persepsi jawaban responden. Skala pengukuran yang digunakan adalah skala interval berupa rating, skala ini bukan menunjukan ukuran yang sesungguhnya.

\section{DAFTAR PUSTAKA}

Antonio, Muh Syafi' (2002), Bank Syariah dan Teori ke Praktik, Gema Insani Press, Jakarta.

Bank Indonesia (2004.), Potensi, Preferensidan Perilaku Masyarakat terhadap Bank Syariah di Wllayah Jawa Barat, www.bi.go.id

Bank Indonesia ( 2001 ), Perbankan Syariah Nasional : Kebijakan dan Perkembangan, www.bi.go.id 
Carragata, Warren (2000). Islamic Finance 101: Shariah Lenders make headway in Indonesia, Asiaweek, July.

Direktorat Perbankan Syariah Bank Indonesia dan Universitas Diponegoro (2000), Potensi, Preferensi dan Perilaku Masyarakat terhadap Bank Syariah di Wllayah Jawa Tengah dan Daerah Istimewa Yogyakarta, Penelitian, Univesitas Diponegoro Semarang.

Erol, Cengiz, and Radi El-Bdour (1989). Attitudes, Behaviour and Patrinage Factors Of Bank Customers Towards Islamic Banks, Intemational Joumal Banking and Marketing, Vol.7 No.6.

Gerrard, Philip, and J. Barton Cunningham (1997)./slamic Banking: A Study in Singapore, Intemational Joumal of Bank Marketing, Vol. 15 No.6.

Imam, Ghozali. (2004). Model Persamaan Struktural, Konsep dan Aplikasi dengan Program Amos Ver. 5.0. Semarang: Badan Penerbit UNDIP.

Khoirunissa, Delta (2003), Consumers'Preference Towards Islamic Banking (Case Study In Bank Muamalat Indonesia and Bank BNI Syariah), Iqtisad Joumal of Islamic Economic, Vol. 4 No. 2.

Khoiruddin, Moh (2003), Preferensi Nasabah Terhadap produk Pembiayaan Bank Syariah, Unit Penerbitan Fakultas Ekonomi Universitas Cokroaminoto, Yogyakarta.

Metawa, Saas A., and Mohammed Almossawi (1998). Banking Behaviour of Islamic Bank Customers: Perspective and Implication, Intemational Joumal of Bank Marketing, Vol. 16 No. 7.

Palilati, Alìda (2007). Pengaruh Nilai Pelanggan, Kepuasan Terhadap Loyalitas Nasabah Tabungan Perbankan Di Súlawesi Selatan, Universitas Haluoleo, Fakultas Ekonomi. Kendari-

Setyowardhani, Hapsari (2002). Analisis Fakfor yang Mempengaruhi Pengambifan Keputusan: Nasabah Bank Syariah (Studi Kasus= Bank Muamalat Indonesia): Universifas:indonesia; Fakultas Ekonomi, Program: Studi Magister Manajemen ${ }_{n}$ Jakarta:

Sudarsono; Herit('2003);, BankiLembaga:Keuangan Syariäh=Deskripsīdan: llustrasi, Ekonisia; Yogyakarta:

Widya; Ranir(2006)-:Rreferensï.can Pèrmintaan Wasyarakat terhadap Prodü:

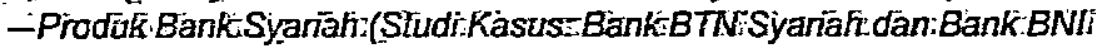

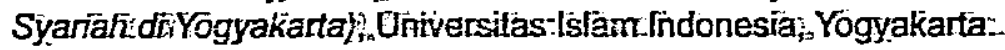


Reni Yendrawati dan Achmad Tirto Sudiro: Analisis Faktor-faktor

Reni Ye $-0-0-1$ -

\section{Lampiran:}

\section{Gambar 1}

Model Pengembangan Hipotesis

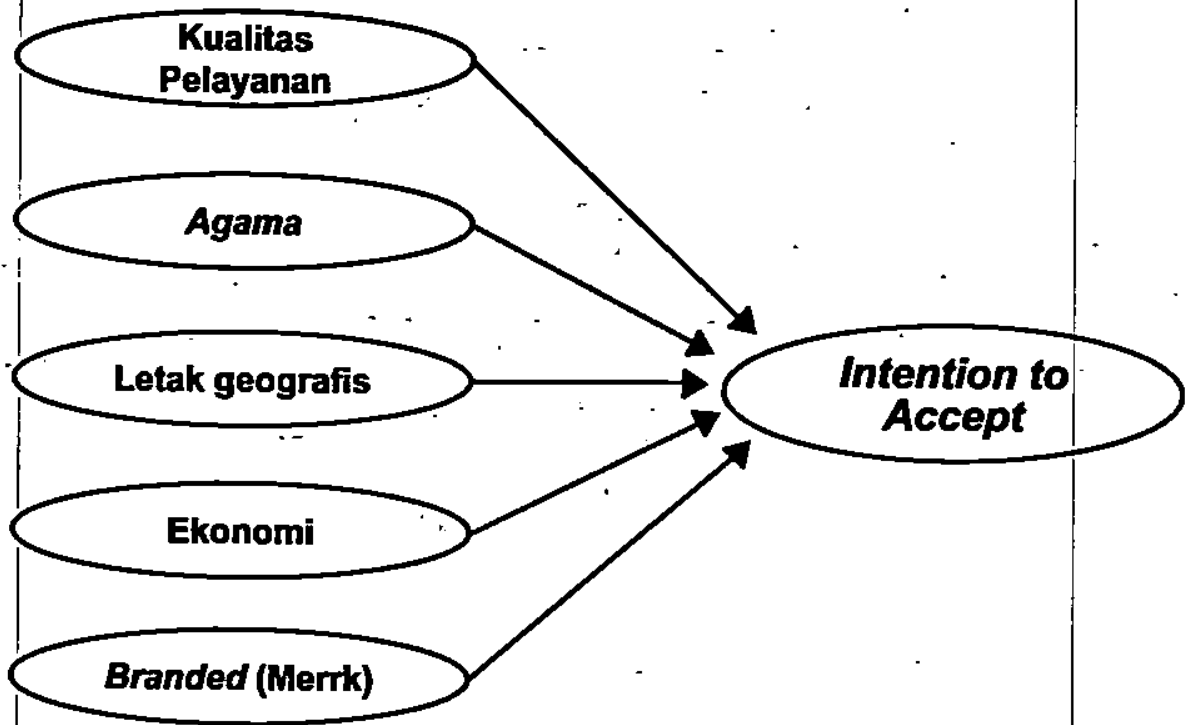

Tabel 1

Hasil Pengumpulan Data

\begin{tabular}{|l|r|r|}
\hline \multicolumn{1}{|c|}{ Keterangan } & \multicolumn{1}{|c|}{ Jumlah } & \multicolumn{1}{c|}{$\%$} \\
\hline Kuisoner yang disebar & 200 & $100 \%$ \\
\hline Kuisoner yang tidak kembali & 43 & $21.5 \%$ \\
\hline Kuisoner yang kembali & 157 & $78.5 \%$ \\
\hline $\begin{array}{l}\text { Kuisoner yang pengisiannya tidak } \\
\text { lengkap }\end{array}$ & 23 & $11.5 \%$ \\
\hline Kuisoner yang memenuhi syarat & 134 & $67 \%$ \\
\hline
\end{tabular}

Sumber. Data Primer yang Diolah 2009. 
Tabel.2

Karakteristik Responden Berdasarkan Jenis Kelamin

\begin{tabular}{|l|r|r|}
\hline Jenis Kelamin & \multicolumn{1}{|c|}{ Jumlah } & \multicolumn{1}{|c|}{$\%$} \\
\hline Laki-laki & 74 & $55 \%$ \\
\hline Perempuan & 60 & $45 \%$ \\
\hline Jumlah & 134 & \\
\hline
\end{tabular}

Sumber: Data Primer yang Diolah 2009.

Tabel 3

Karakteristik Responden Berdasarkan Wilayah Tempat Tinggal

\begin{tabular}{|l|r|c|}
\hline Kabupaten/Kota & Jumlah & $\%$ \\
\hline Sleman & 62 & $46 \%$ \\
\hline Bantul & 27 & $20 \%$ \\
\hline Yogyakarta & 30 & $23 \%$ \\
\hline Kulonprogo & 15 & $11 \%$ \\
\hline Jumlah & 134 & \\
\hline
\end{tabular}

Sumber: Data Primer yang Diolah 2009.

Tabel 4

Karakteristik Responden Berdasarkan Jenis Pekerjaan

\begin{tabular}{|l|r|r|}
\hline Jenis Pekerjaan & \multicolumn{1}{|c|}{ Jumlah } & \multicolumn{1}{l|}{$\%$} \\
\hline Mahasiswa & 50 & $37 \%$ \\
\hline Pegawai Negeri & 17 & $13 \%$ \\
\hline Pegawai Swasta & 30 & $22 \%$ \\
\hline Wirausaha (UKM) & 37 & $28 \%$ \\
\hline Jumlah & 134 & \\
\hline
\end{tabular}

Sumber: Data Primer yang Diolah 2009. 
Reni Yendrawati dan Achmad Tirto Sudiro: Analisis Faktor-faktor ...

-

Tabel.5

Karakteristik Responden Berdasarkan Tingkat.Pendidikan Akhir

\begin{tabular}{|l|r|r|}
\hline Pendidikan & Jumlah & $\%$ \\
\hline SD & - & \\
\hline SMP & 2 & $0.03 \%$ \\
\hline SMA & -33 & $24.64 \%$ \\
\hline Sarjana & 90 & $67.16 \%$ \\
\hline Pasca Sarjana & 9 & $0.07 \%$ \\
\hline Jumlah & 134 & \\
\hline
\end{tabular}

Sumber: Data Primer yang Diolah 2009.

TABEL 6

Regression Weights: (Group number 1 - Default model)

\begin{tabular}{|l|rrrrr|}
\hline & \multicolumn{1}{|c}{ Estimate } & S.E. & C.R. & P & Label \\
\hline eco1 —- eco & 1.000 & & & & \\
eco6<- eco & .868 & .303 & 2.860 & .004 & par_1 \\
eco2<- eco & 1.162 & .295 & 3.934 & $\ldots$ & par_2 \\
eco5<- eco & 1.159 & .316 & 3.667 & $\ldots$ & par_3 \\
eco4 <- eco & 1.253 & .344 & 3.638 & $* *$ & par_4 \\
eco3 <- eco & 1.256 & .338 & 3.720 & $* *$ & par_5 \\
\hline
\end{tabular}

TABEL.7

Regression Weights: (Group number 1 - Default model)

\begin{tabular}{|l|rrrrr|}
\hline & Estimate & S.E. & C.R. & P & Label \\
\hline relig1 <- relig & 1.000 & &. & & \\
relig6 <- relig & -1.707 & .404 & 4.227 &.$* *$ & par_1 \\
relig2 <- relig & 1.681 & .408 & 4.122 & $* * *$ & par_2 \\
relig3 <- relig & 1.221 & .303 & 4.034 & $\ldots$ & par_3 \\
relig4 <- relig & 1.786 & .410 & 4.354 & $* *$ & par_4 \\
relig5 <- relig & 1.784 & .421 & 4.234 & $\ldots *$ & par_5 \\
\hline
\end{tabular}




\section{TABEL.8}

Regression Weights: (Group number 1 - Default model)

\begin{tabular}{|c|c|c|c|c|c|}
\hline$\cdot$ & Estimate & S.E. & C.R. & $P$ & Label \\
\hline qof1 <- qof & .1 .000 & & & & \\
\hline qof6 $<-$ qof & 1.344 . & .205 & 6.571 & $* * *$ & par_1 \\
\hline qof11 $<-$ qof & 1.190 & .192 & 6.205 & $* * \star$ & par_2 \\
\hline qof5 $<-$ qof & 1.444 & .219 & 6.597 & $* * *$ & par_3 \\
\hline qof4 $<-$ qof & 1.381 & .228 & 6.064 & $* *$ & par_4 \\
\hline qof3 $<-$ qof & 1.440 & .222 & 6.489 & $\cdots$ & par_5 \\
\hline qof2 $<-$ qof & 1.233 & .194 & 6.368 & *** & par_6 \\
\hline gof7 <- qof & 1.640 & .250 & 6.561 & $\cdots$ & par_7 \\
\hline qof8 $<-$ qof & 1.463 & .262 & 5.592 & $* * *$ & par_8 \\
\hline qof9 $<-$ qof & .904 & .176 & 5.130 & $* * *$ & par_9 \\
\hline qof $10<-$ qof & 1.392 & .221 & 6.294 & $*$ & par_10 \\
\hline
\end{tabular}

TABEL 9

Regression Weights: (Group number 1 - Defaúlt model)

\begin{tabular}{|l|rrrrl|}
\hline & Estimate & S.E. & \multicolumn{1}{l}{ C.R. } & P & Label \\
\hline geo1 <- geo & 1.000 & & &. & \\
geo3 < - geo & 1.038 & .108 & 9.610 & $* *$ & par_1 \\
geo4 <- geo & 1.236 & .117 & 10.576 & $* * *$ & par_2 \\
geo2 <- geo & .914 & .112 & 8.134 & $\cdots$ & par_3 \\
\hline
\end{tabular}

TABEL.10

Regression Weights: (Group number 1 - Default model)

\begin{tabular}{|l|rrrrr|}
\hline & \multicolumn{1}{|c|}{ Estimate } & S.E. & C.R. & P & Label \\
\hline bra1 <- bra & 1.000 & & & & \\
bra4 $<-$ bra & .761 & .108 & 7.061 & $* *$ & par_1 \\
bra3 <- bra & .947 & .115 & 8.260 & $* * *$ & par_2 \\
bra2 <- bra & 1.159 & .114 & 10.203 & $* * *$ & par_3 \\
\hline
\end{tabular}


Reni Yendrawati dan Achmad Tirto Sudiro: Analisis Faktor-faktor ...

-

TABEL 11

Regression Weights: (Group number 1 - Default model)

\begin{tabular}{|l|llllll|}
\hline & & Estimate & S.E. & C.R. & P & Label \\
\hline aksep1 <- aksep & 1.000 & $\ddots$ & & & \\
aksep2 <- - aksep & 1.317 & .435 & 3.025 & .002 & par_1 \\
aksep5 <- aksep & 1.318 & .435 & 3.029 & .002 & par_2 \\
aksep3 <- aksep & 1.092 & .393 & 2.780 & .004 & par_3 \\
aksep4 <- aksep & 1.295 & .423 & 3.065 & .002 & par_4 \\
\hline
\end{tabular}

TABEL.12

Hasil Uji Reliabilitas Variabel Penelitian

\begin{tabular}{|l||l|c|c|}
\hline No & \multicolumn{1}{|c|}{ Nama Variabel } & Cronbach's Alpha & Keterangan \\
\hline 1 & Ekonomi (eco) & 0.701 & Reliabilitas diterima \\
\hline 2 & Agama (relig) & 0.813 & Reliabilitas baik \\
\hline 3 & Kualitas Pelayanan (qof) & 0.897 & Reliabilitas baik \\
\hline 4 & Letak Geografis/Demografi (geo) & 0.868 & Reliabilitas baik \\
\hline 5 & Faktor Branded/Merk (bra) & 0.844 & Reliabilitas baik \\
\hline 6 & Keinginan untuk Menerima (aksep) & 0.881 & Reliabilitas baik \\
\hline
\end{tabular}

TABEL 13

Regression Weights: (Group number 1 - Default model)

\begin{tabular}{|c|c|c|c|c|c|c|c|}
\hline & & & Estimate & S.E. & C.R. & $\mathbf{P}$ & Label \\
\hline aksep & $<-$ & eco & .085 & .155 & .551 & .582 & \\
\hline aksep & $<-$ & relig & .464 & .144 & 2.529 & .011 & \\
\hline aksep & $<$ & bra & .056 & .143 & .389 & .697 & \\
\hline aksep & $<-$ & geo & .136 & .072 & 1.901 & .057 & \\
\hline aksep & $<-$ & qof & .260 & |155. & 1.676 & .094 & \\
\hline
\end{tabular}

Sumber: Data Primer yang Diolah 2009 


\section{TABEL 14}

Standardized Regression Weights: (Group number 1 - Default model)

\begin{tabular}{|l|l|r|}
\hline & & Estimate \\
\hline aksep <- & eco & .089 \\
\hline aksep <- & relig & .583 \\
\hline aksep <- & bra & .057 \\
\hline aksep <- & geo & .304 \\
\hline aksep <- & qof & .269 \\
\hline
\end{tabular}

Sumber: Data Primer yang Diolah 2009 